contemplate the abolition of the plague passport system in the near future, and the introduction in its place of a system under which people arriving from infected areas will be required to notify local authorities of their arrival. The matter is now engaging the attention of the Government.

\section{Plague in Bihar.}

Reports received by the press and from private sources state that plague is playing havoc in many of the towns and villages of Bihar, and there is quite a panic among the people owing to the virulent form in which it has broken out. This year the visitation appears to be worse than ever before.

Plague in the Punjab.

Mortality from plague in the Punjab has steadily increased during the current month. There were 2314 cases with 1702 deaths in the week ended Iarch 14th. Every district except Lahore is now infected.

\section{Agra Medical Students' Strike.}

The medical students at Agra struck on March 15th. They left the hostel and passed the day and night in open spaces. Maltreatment is alleged to be their chief complaint. The authorities deny the students' version, and say that they were in the dark as to this derelopment, which took place with great suddenness and secrecy. Until evening the students were playing games, and there was no inkling of any grierances on their part. The authorities believe this to be connected with the Lahore medical students' strike, but cannot give any definite cause with certainty.

Successful Use of Stovaine at Bangalore.

Two successful major operations have been per. formed by Major R. F. Standage, residency surgeon at Bangalore, who used the spinal anæsthetic known as storaine, in the presence of the local surgeons. Major S. G. S. Haughton, R.A.M.C., who is travelling through India to familiarise the hospitals with the use of the drug, demonstrated the technique to the meeting. March 18th.

\section{Uartespondente.}

"Audi alteram partem."

\section{THE RELATION OF TUBERCULOSIS ANB} TYPHOID FEVER.

\section{To the Editor of THE LANCET.}

SIR,-I should like to make a short comment and criticism on the annotation in THE LANCET of April 4th with the abore heading, to which my attention has been drawn.

Without an actual record of the figures of $m y$ cases and of those of my colleagues at the London Hospital it would be rash to deny that tuberculosis erer follows typhoid so closely that its onset and derelopment can be attributed directly to the influence of the typhoid, but I cannot recall to mind any such case having occurred, and I should require details of a large number of cases before being convinced of such a sequence between the two diseases. If, how. ever, such a sequence has been observed by those competent to express an opinion, founded on an observed frequency of result, I would then be in hearty agreement with Colonel Woodruff's view that it must in some way be due to too rigid an observance of the old canons of the dietetic treatment of typhoid patients.
If I am right, as I believe I am, in saying that I have not observed tubercle following on typhoid, while other observer's note the frequent sequel, the difference must be due in some way to the treatment I adopt. For many years now I have discarded altogether any routine in the dietary of my typhoid patients and have adopted a plan which, summed up in a sentence, is: "Feed a typhoid according to his appetite," controlled only by frequent examination of his abdomen and stools, the former giving a very early warning of any tendency to distension, the latter being a measure of the completeness of digestion (all ordinary articles of diet being allowed except fruits with small seeds, grapes being especially forbidden owing to the almost hooklike tip of their pips).

My first published article on the subject appeared in the British Medical Journal for 1906, and in that article I pointed out that I had never had any reason to regret my line of practice, and I can say that my experience since has not led me in any way to modify my views. There was also another very striking point which I brought out-viz., that having adopted my plan for some years before I published my results, I had practically forgotten that there were such things as complications and sequelæ of typhoid, because I had seen so few examples amongst the 200 or so cases upon which my paper was founded; I had had my proportion of deaths from toxæmia, but my proportion of complications and sequelæ was almost infinitesimal, while I gained nearly a fortnight in the arerage duration of the stay in hospital. I published a fuller article on the matter in the American Practitioner for $\mathrm{Hay}$ and June, 1913.

I am, Sir, yours faithfully,

Harley-street, W., April 20th, 1914.

Fred. J. ShItTH.

\section{TONSILS AND ADENOIDS IN CHILDREN.} To the Editor of THE LANCET.

SIR,-The plea for fewer operations made by Mr. T. B. Layton in THE LANCET of April 18th is rery timely. As a responsible school medical officer I may say I have from the first fostered a conservative attitude on this subject. Undoubtedly the removal of tonsils and adenoids in carefully selected cases is an operation of the highest possible value, and should be urged as a necessity. There are, howerer, two ol three points raised in $\mathrm{Mr}^{\circ}$. Layton's paper, which I propose briefly to comment upon, as my own experience has led me to exercise my judgment.

1. The presence of carious teeth and septic mouths as a cause of glandular enlargement. Not many months ago I was asked to issue a roucher for an operation on the tonsils of a school child who had not been previously medically inspected under the Act of 1907. I was informed that the local doctor had said that removal of tonsils was necessarv. As I strongly hold that no rouchers for operation should be issued by an education authority unless the child has been previously medically inspected, I made arrangements to see this child myself when visiting the neighbourhood in connexion with some county work. The tonsils were only moderately enlarged and were, in $\mathrm{my}$ opinion, distinctly consequent upon eight carious teeth in the child's jaws. To have removed the tonsils with the mouth in such a condition would, in my opinion, have been bad surgery. I declined to issue a voucher for removal of tonsils, and pointed out that the dental surgeon was the proper person to deal with the case. I shall be disappointed if the tonsils do not undergo 
spontaneous cure when once the teeth are properly attended to.

2. The second point is with respect to infection with scarlet fever, \&c., as a post-operative complication. With all due respect, I beg to differ from $\mathrm{Mr}$. Layton that the disease is incubating in the child when the operation is done. On the contrary, I am of opinion that the mechanical injury to the tissues inseparable from the operation is an evolutionary factor which enhances the pathogenicity of some almost ubiquitous mouth micro-organism and directly produces a de novo case of scarlet fever in a susceptible child.

The evolutionary factor is unquestionable in post-operative pneumonia, as admitted by Mr. Layton, and I am of opinion from cases which have come under my observation that it is equally responsible for some of the cases of post-operative scarlet fever. (We sometimes see a similar sequel after burns.) The practical suggestions made by Mr. Layton as to preliminary use of formalin tablets for a few days before operation, and the adoption of Professor Killian's rule never to operate if the temperature be above $99^{\circ} \mathrm{F}$, deserve wide recognition and adoption.

I am, Sir, yours faithfully,

Norwich, April 20th, 1914 J. T. C. NASH.

\section{THE RAPID INCREASE OF DIABETES IN WOMAN.}

To the Editor of THE LANCET.

SIR,--Until quite recently we were accustomed to look upon diabetes mellitus as a disease which attacked males much more frequently than females, the proportion being, in fact, about 3 to 1 . During the last 25 years, however, there has been, at least in this country, an extraordinarily rapid inclease of the disease in both sexes, and such a much more marked increase in the case of females than males that the records even of the Registrars. General of England, Scotland, and Ireland respectirely would seem to indicate that rery soon the frequency of the disease in females will surpass and greatly exceed that in males.

The following returns of death from diabetes specifically as furnished by the three RegistrarsGeneral of the United Kingdom, cannot fail to make us apprehensive that some prejudicial change in the mode of liring in this country must have taken place during the last quarter of a century, which is accountable for the great and rapid increase of the disease.

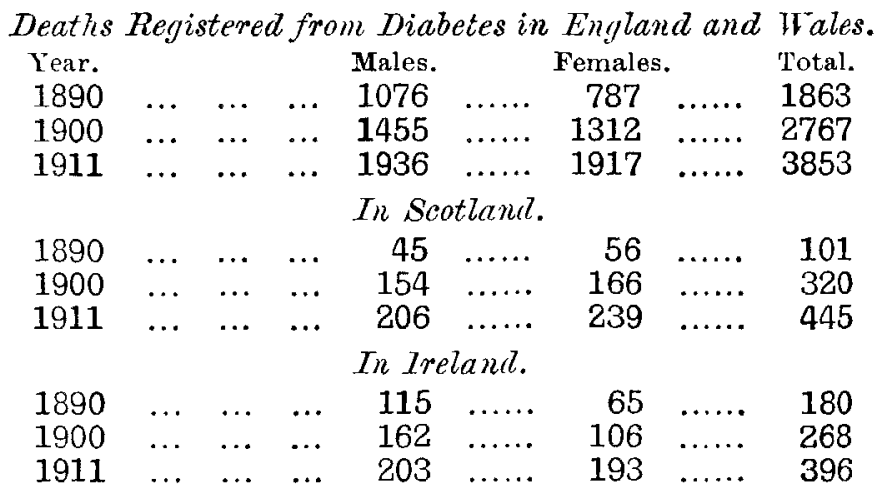

From the aforesaid returns, moreover, it is impossible for us to form anything like an adequate idea of the alarming increase of diabetes, for it must be remembered that very many more diabetics die every year than the returns of the various Registrars-General disclose. A state of hyperglycamia lowers the resisting powers of the body and so renders the individual more susceptible to other diseases, to diseases which are apt to prove more fatal than usual because of the excess of sugar in the blood, and under such circumstances the death is registered under the intercurrent and not under the fundamental disease. The existence even of the diabetic state may neither have been known to the patient nor the medical attenclant, and it may have escaped detection, for it is well known that duxing acute febrile disenses in diabetics the sugar often disappears temporarily from the urine.

It is undoubtedly a noteworthy fact that in the case of Scotland the death returns from diabetes are in 1911 quadruple what they were in 1890, and that in Ireland as well as England the specific death-rate from this disease is to-day twice what it was 25 years ago. Confronted with such facts we are impelled to believe that the great and rapid increase of the disease must be due to some influ. ence or influences of a prejudicial character which have become more prevalent during the last quarter of a century. In my opinion the most important retrograde change in our mode of living which is disturbing the metabolic processes in our bodies and rendering us more susceptible to a state of hyperglycemia is that which concerns our foodstuffs. Twenty-five years ago the question of adding chemical preservatives to our foodstuffs was unthought of, the practice of polishing rice and thus depriving this cereal of some of its most important mineral substances was unknown, and so, too, was the roller process of milling wheat as well as the bleaching of an already too im. porerished flour. If the metabolic processes in our bodies are to be maintained efficiently the ingested foods will hare to be more wholesome and less tampered with than they are to-day.

I am, sir, yours faithfully,

JAires OLIVER, M.D. Edin., F.P.S.E.

Harley-street, W., April 11th, 1914.

\section{ALLEGED TIALINGERING UNDER THE INSURANCE ACT. \\ To the Editor of THE LANCET.}

SIR,-The return of many insured patients to work on the appearance in their district of the medical referee has been widely commented upon. It has been hailed as an administrative triumph and as defending the Insurance Act, if not from the fear of its enemies, at least from danger of im. pending bankruptcy. A sympathising press has spilt much ink and shed virtuous tears over the wickedness of fraudulent patients and conniring doctors, as if further inquiry into the merits of the case were needless, and nothing remained to be attended to but the punishment of the guilty. The surprising thing has been that members of the medical profession should have been ready to join in the general outcry, and this fact it is which, perhaps more than anything else, accounts for the partly perplexed and mainly indignant feeling among panel practitioners.

In order to ascertain what foundation there may be for the allegations that have been made, I have looked up my notes of the few cases of my own in which the question of malingering has been raised, with results which have seemed to me in. structive, and am writing this in the hope that others may be led similarly to examine the matter for themselves, and, it may be, to take a more favourable view of the morale both of the insured and of 